\title{
Click "Here" to Post a Comment: Legend Discussion and Transformation in Online Forums
}

Jeffrey S. Debies-Carl

University of New Haven, jdebiescarl@newhaven.edu

Follow this and additional works at: https://digitalcommons.newhaven.edu/sociology-facpubs

Part of the Sociology Commons

\section{Publisher Citation}

Debies-Carl, J.S. (2021). Click "Here" to Post a Comment: Legend Discussion and Transformation in Online Forums. Journal of Folklore Research 58(2), 31-62.

\section{Comments}

This is the submitted version of the article published in Journal of Folklore Research, volume 58, issue 2, MayAugust 2021, pages 31-62.

This pre-print is a working paper.

Full-text access is available to current University of New Haven community members. 


\title{
CLICK 'HERE' TO POST A COMMENT: LEGEND DISCUSSION AND TRANSFORMATION IN ONLINE FORUMS
}

\author{
Jeffrey S. Debies-Carl \\ University of New Haven \\ jdebiescarl@newhaven.edu
}

\begin{abstract}
The internet has become the predominant source of dissemination for dubious legends, ranging from medical misinformation to conspiracy theories and supernatural encounters. Here, questionable claims circulate and are discussed, often with consequences - sometimes even deadly ones - in real life. Building on previous work in this area, I examine contemporary legends as they are told and discussed in online forums. Drawing on Nancy Baym's outline of the characteristics of the internet that distinguish it from other forms of communication, I analyze how the internet's interactivity, temporal structure, social cues, storage, replicability, reach, and mobility affect the form and function of the legend process. I find that 1) the internet subverts some of the traditional characteristics of the legend-telling process, but 2) paradoxically, other characteristics of the internet actually reinforce or valorize traditional elements, while 3) surprisingly, sometimes the internet has no effect at all even in areas where we might expect the most dramatic effects. These findings provide significant insights into the role the internet plays in today's world where bizarre claims increasingly characterize everyday social and political life. They shed light on how the internet provides a window into our concerns while simultaneously exacerbating them.
\end{abstract}

\section{Introduction}

Both legends and legend-tripping have proliferated across the web. Researchers have examined a range of legend-related behaviors online, including legend-formation (Boyer 2013), legend transmission (Fernback 2003, Soltero 2016), and legend discussion (Langlois 2014). Legends associated with legend-trips have also received some attention, albeit to a lesser extent. For example, Peck (2015) has described how people might look for and even find a supernatural entity in real life that originally only existed as an online meme. Meanwhile, Tucker (2017) has examined how smartphones play an increasingly important role during legend-trips. Conversely, Tolbert (2013) illustrated how the internet enables 'reverse ostension', whereby a coherent legend is woven together through the collaboration of many people. Taking things a step further, Kinsella (2011) and McNeill (2015) have argued that legend-trips can take place almost entirely online.

Legends may be thriving online but, like other forms of folklore, the internet presents challenges for understanding them. Research has illustrated how the internet is no mere extension of oral culture, but neither is it simply a new means of storing and retrieving texts. Rather, it is a hybrid medium, expressing characteristics of both forms of communication (Howard 2005, 2008a, 2008b). Consequently, many scholars have pointed to the need for further research to unravel the puzzles of online discourse and to shed new light on old questions. 
Trevor Blank has called for work of this sort, noting that "the permeation of technologically mediated folklore undoubtedly does mean that new and compounding research should be undertaken in order to complement (and possibly extend or amend) existing research on vernacular expression" (2012: 3, emphasis in original). Examining the folklore process online "presents the opportunity to revisit and recontextualize [it] en route to garnering new insights on contemporary folk culture" (p.3).

There is a crucial need for further research to aid our understanding of internet legends. First, legends and legend-inspired behavior have proliferated online. As McNeill and Tucker have observed, 'While it may seem a strange kind of 'place,' the Internet is a growing setting for a number of contemporary legend-trip experiences" (2018: 26). Second, legends and related claims have entered into the mainstream of American politics, often with disastrous consequences. There have been notable cases where online conspiracy legends - a type of folklore (Walker 2014) — have inspired legend-trips. In 2016, for example, an active shooter visited a Washington, D.C. pizzeria to investigate legends of an occult, child abduction ring he had read about online (Debies-Carl 2017). More recently, "hospitals encountered a spike in the referral of poisoning cases for the ingestion of industrial-grade ethanol" after claims circulated online that drinking or gargling the substance could prevent the spread of COVID-19 and that many people allegedly cured themselves this way (Mehrpour and Sadeghi 2020: 2259).

In this study, I examine the relationship between specific characteristics of the internetthose which make it distinct from both oral and textual communication - and online legend narration and discussion. First, I review the characteristics of legends and the specific aspects of the internet that might modify their traditional form and function. Then, I introduce my data and general approach before sharing the results of my analysis. I conclude by considering the significance of these results in the modern world.

\section{Oral Traditions in a Digital Age}

A precise definition for legends has long been debated (Dégh 2001), because of their complex nature. Nonetheless, several key elements usually distinguish them from other forms of discourse. A legend includes a sort of narrative "account of past happenings" that might have really happened (Ellis 2003: 167). Legends possess characteristics that make them engaging and difficult to ignore. First, they are typically strange, often even supernatural, which sparks interest in their audiences (Brunvand 1981). Second, they are not innocuous. Rather, legends claim that there is some sort of danger at hand - either to personal safety or to cherished values - or a promise of reward, that further engages listeners (Ellis 2003). Moreover, their claims typically seem possible, if not plausible. It is not immediately obvious whether they are true (Brunvand 1981). Instead, people must spend time pondering them and may not reach a firm conclusion (Kinsella 2011).

Legends are also incomplete tales. They feature a "fragmentary, incomplete form" (Dégh 1971:62). They might not have a clear beginning or ending, omit details like the setting or people involved, and so forth. When people hear accounts like these, they try to fill in the blanks to make sense of them (Tucker 2007). To do so, they draw not only on their own ideas, but on discussion with others. Because of these various characteristics, discussion often becomes debate and argument. Thus, a legend is more of a dialogue than a narrative. As Ellis observed, "the legend is not self-contained but is part of an ongoing conversation, [...] the text cannot be 
separated from the legend-telling event, since the performance arises from the group's concerns and in turn provokes further discussion and performance" (2003:11). People enthralled with the legend feel compelled to discuss it intensely and argue over it: its veracity, its setting, its meaning, its missing pieces, and so forth. In fact, Dégh argued that debate is one of the defining characteristics of the genre, saying that a "legend is a legend once it entertains debate about belief" (2001: 97). All such discussion-including variations, interpretations, and interpolated details - become a part of the evolving dialog.

Legends are not simply told through words, they are also acted out through deeds: a process called 'ostension' (Dégh and Vázsonyi 1983). This occurs when, because of their compelling characteristics, individuals entertain the possibility that a legend might be true and react accordingly. Through their actions, they might attempt to mitigate its perceived threats or, conversely, to act it out so that they might become a part of the legend themselves. In this way, legends can have real consequences. Ostension might also take the form of a 'legend-trip': an attempt to find out whether a legend is true through first-hand investigation of its claims (Hall 1973).

It is impossible to fully appreciate the place of legends in modern life without considering their expression online. The internet is an important medium for social discourse (McNeill 2009). Indeed, "the most popular and far-reaching means of transmitting and receiving folklore today is often computer-mediated" (Blank 2015: 5, emphasis in original). A plethora of traditional vernacular forms and practices has found new life on the web, including such diverse examples as joke memes (Blank 2018), chain emails (Kibby 2005), and web forum discussions of old fairy tales (Raufman and Ben-Cnaan 2009). Beyond these web-based rebirths of older expressions of folklore, the internet has also given birth to both radically changed and entirely new modes of discourse, like personal or 'vanity' webpages (Howard 2008a), Amazon.com product reviews (Blank 2015), and 'creepy pasta' (Boyer 2013).

The internet enables these emergent forms because it is more than just a new medium for traditional communication. Nancy Baym (2010) provides a useful way to think about the revolutionary characteristics of computer-mediated communication. She outlines seven dimensions along which media can be evaluated and compared: interactivity, temporal structure, social cues, storage, replicability, reach, and mobility. 'Interactivity' is the extent to which a given mode facilitates exchange between people. 'Temporal structures' can be synchronous or asynchronous, permitting interaction in real time or requiring delay between exchanges. Modes may vary in the 'social cues' they can communicate too, including, for example, facial expression or tone. 'Storage' refers to how easily and accurately communication can be recorded. 'Replicability' deals with the degree of fidelity with which an interaction can be replayed or passed on to others. 'Reach,' intuitively, encompasses the extent to which a message can spread to more people in other places. Lastly, 'mobility' describes whether a mode of communication is stationary or portable.

Modes of communication rank differently on these dimensions and this affects their character. For example, oral exchange allows considerable back-and-forth conversation (interactivity) and non-verbal communication (social cues), but it is more limited in terms of how many people can participate at one time (reach). Likewise, as soon as a word is spoken, it is gone (storage) and will be difficult to repeat (replicability) through memory. Of course, someone can record the spoken word - through writing for example-but this introduces a new medium. 
Written texts might increase storage and replicability, but they greatly reduce both interactivity and social cues while also changing the temporal structure of communication.

The internet further complicates matters. It can approximate or facilitate many of the aspects of oral communication, like real time interaction through applications like Zoom. However, it also possesses characteristics of text-based communications. For example, many websites consist primarily of text with little interactivity - especially synchronous interactionbetween creators or other users. The internet is not simply a combination of modes of communication - it is hybrid (Blank 2018; Fernback 2003: Howard 2005, 2008a, 2008b) displaying characteristics of both simultaneously while also allowing these dual natures to interact in new and powerful ways. For example, an email might begin as a short piece of text exchanged among a small group of friends (interactivity). However, because this mode of communication is asynchronous (temporal structure), easily stored and transmitted (storage and replicability), and can be forwarded infinitely (reach), it could ultimately reach a vast number of people. It could even transfer to diverse applications with characteristics all their own like video blogs or web forums.

Because of its distinctive characteristics, the internet modifies how folklore operates online (e.g. Howard 2008b, Langlois 2014, Raufman and Ben-Cnaan 2009). It also influences offline folk processes since these two realms are increasingly intertwined (Blank 2018:4). We can, for instance, talk online about an experience we had in the physical world or tell people inperson about something we experienced on the web. In short, not only can we read legends online, we can use this information to interact with these legends in a variety of ways. We can forward legends to friends through email, ask questions and discuss legends with other website users, post descriptions of our own legend trip experience, listen to video or audio recordings of other people's legend trips, or even upload whole legend-trip recordings of our own - even while we are still on location in a haunted house or cemetery.

Guided by Baym's characteristics, this paper thus asks key questions about legends in online forums. Do they feature the same content and form as their offline equivalents? How does the asynchronous nature of forums affect interactivity and discussion? How does their asynchronous structure affect discussion and interactivity? Does greater capacity for storage and replicability result in more copied rather than creative material? Does greater reach mean that legends are less bound by local interests and bounded communities? In what ways does mobile internet access impact legend narration? I will provide answers to these questions in the remainder of this paper and offer conclusions about the overall effect of the internet on the legend process.

\section{Legend-Telling and Legend-Tripping Online}

For this study, I drew on data I collected over a five-year period for a project investigating legend-tripping. This included extensive fieldwork and a comprehensive analysis of textual and video accounts, found both online and off, spanning 86 legend-tripping locations. Like previous researchers, for this paper I concentrated on the portion of the data drawn from web forum discussions of legends (e.g. Raufman and Ben-Cnaan 2009) and their associated settings, including also blog (e.g. Howard 2005) and video posts with an interactive forum component (e.g. Boyer 2013). Websites like this thus include elements that allow, and blur the distinction between, both oral and textual communication (Blank 2018, Fernback 2003). These 
forums took three possible forms: 1) large sections of text by a single author summarizing a legend followed by a forum, 2) a video posting about a legend followed by a forum, or 3) a standalone forum. The sites consisted primarily of personal blogs, news stories, social media (e.g. Youtube, Facebook), and websites that served as 'directories' for multiple legends. The latter typically provided a separate page for each legend that was organized very much like the other text-based sites (e.g. https://www.haunted-places-to-go.com/).

My method was similar to Fernback's (2003) non-participant observation in which I 'observed' the interactions of individuals without actively contributing. Sensitive to the possible ethical challenges of this approach, I followed Kozinet's (2010) guidelines for online ethnography. First, I only accessed information on publically available websites that did not require registration to view since these minimize privacy expectations. Second, since I did not introduce myself as a researcher, neither did I interfere or participate in forum discussions, record sensitive or identifying information, nor analyze private forums that required registration to participate. ${ }^{1}$ In fact, given the asynchronous nature of forums, announcing myself would prove impossible considering some users had posted their message and left, permanently, years earlier while others might show up years after my project has concluded. This issue illuminates how online research can yield findings remarkably similar to traditional approaches while simultaneously departing radially from them: an issue I illustrate further below. When quoting sources, I retained nearly all of the original grammar and syntax, except where I needed to cut material for purposes of space and in rare cases to improve comprehension. All modifications are noted in brackets. Also, although web-users' names typically did not seem to reveal real identities, I have excluded these as well out of caution.

\section{Legend-Telling}

The first piece of content on most sites is typically a standard retelling of a specific legend or series of legends related to a particular place. This could take the form of either a textbased narrative or a comparable segment of monologue in a video. Regardless of delivery method, these computer-mediated legend accounts feature many of the same characteristics as oral legends, outlined above, which serve to engage audiences with their claims.

For example, several of the forums I examined were dedicated to something called a 'melon head': a creature said to roam the edges of civilization in certain parts of the country, including Connecticut. According to one of these narratives: "one of the local stories we all heard about was about a group of giant-headed mutants who lived on the outskirts of town, a band of inbred freaks" (Bendici 2010). The opening legend-narrative of a YouTube video tells a version of their tale:

[T]here was an asylum for the criminally insane erected in the mid-1800s, somewhere near the border of Trumbull and Monroe [Connecticut]. One autumn, a group of the detained started a fire and burned down the asylum. Afterwards, the wreckage was searched. All of the staff were identified and believed to be burnt alive, but a handful of the institutionalized were left unaccounted for. Those who escaped knew that reentering one of the nearby towns would only lead to recapture. So rather than return to society, these misfits chose to remain extremely secluded. The risk of being caught made it near impossible to farm, so these individuals scraped by eating wildlife, which became scarce during the harsh Connecticut winters. Fearing outside contact, they quickly turned to 
inbreeding for procreation. The combination of cannibalism, malnutrition, and rapid inbreeding created a subspecies of human with physical deformities, mental retardation, and a penchant for violence. (Fear Channel 2013)

Narratives like this feature many of the hallmarks of an oral legend, including accounts of alleged past happenings, warnings, and threats to morals and values (Ellis 2003). We learn about the quasi-historical origin of the melon heads, how they came to be in their current condition, and implications of ongoing encounters with them. We are warned here, and in similar forums, "they're supposedly pretty deadly" (CT Boom 2017). They are "ready to prey Deliverance-style on whoever was careless or unfortunate enough to wander into their midst" (Bendici 2010). Not only is bodily harm a danger, but social values are threatened as well. This is evident in part through the invocation of traditional taboos: incest, cannibalism, and random violence. The monsters engage in and symbolize morally incorrect behavior, but the threat of the monstrous is also that we might become monsters ourselves through similar lapses (Cohen 1996). In another version of the legend, we learn that "Some people say they eat anyone they catch, while others say they do something even worse: turn them into Melonheads"( Muise 2015a). Moral concerns are also evident in the treatment of the melon heads. The legend credits their abuse while in the custody of authorities with precipitating the horrors that followed and thus calls into question the trustworthiness of society's institutions.

In addition to their content, there is also the form of online legends to consider. Here there are both similarities to, and radical departures from, oral legends. First, even when comparing multiple websites, it is evident that online legend are not complete stories. In the case of the melon heads, there are multiple, competing and vague claims evident. For example, there is no clear motivation for their attacks on wandering teenagers. Are they defending their territory, hunting for food, or just looking for revenge? Likewise, their origin is also unclear. While the account above suggests they were prisoners, others claim they were orphans (Ackerman 2014) or mental patients (CT Boom 2017). Institutionalized, they were subject to abuse or medical experiments. These, in turn, caused their deformities (Muise 2015b) or, alternatively, were conducted because of preexisting deformities. Any of these uncertain possibilities, of course, provide the website visitor with additional moral issues to consider. Just like oral legends, the "fragmentary, incomplete form" (Dégh 1971:62) of online legends encourages active engagement from its audience.

Like oral legends, online legends also tend to feature a "dichotomous structure" (Dégh 1969: 78). This means that the narrator typically begins by telling the legend as a 'fabulate'relating a third-person account of things that happened to someone else. Then, they move on to recount their own experiences at the legendary site as a first-person 'memorate.' The 'Damned Connecticut' website provides examples of one version of this style. It consists of a series of webpages dedicated to separate local legends, with each entry clearly divided between fabulate and memorate components. For example, the page for 'Gunntown Cemetery', in Naugatuck, Connecticut, begins with a section labeled, 'The Damn Story' (Bendici 2019). Here, the reader learns about the history of the cemetery and some of its uncanny phenomena: it is located "in the Millville section of Naugatuck," it "dates back over two centuries to 1790," and there is a "supposed[ly] high level of haunting that occurs here." The text goes on to summarize some of these past happenings - like mysterious music and apparitions - with a half-serious tone appropriate for discussing legends. The next section is labelled, 'Our Damned Experience' and shifts abruptly to a discussion of the author's legend-trip to the cemetery. 


\section{$<$ Figure 1>}

In this example, the narrative thus shares the dichotomous structure of oral legends, but its style is simultaneously dissimilar. Dégh (1969) noted that oral legend-tellers typically switch freely and organically between both forms as needed, but here we see instead that the shift from fabulate to memorate is clearly demarcated and abrupt. This style is more characteristic of written communication than oral (Fernback 2003) —which is not surprising considering it is text - but other styles are evident online too. For example, the opening narrative on another website about Gunntown Cemetery is structured differently. It begins by describing the cemetery - its age, size, and main features - then moves on to consider some supernatural claims for the location:

This place is known for 2 things. Weird and weirder! On most times visiting this place, Gunntown kind of grows on you. It makes you feel like somehow you have been here before and its not really a cemetery. [...] The chill will come from the old time music you can always hear playing as if a coffin was buried with a record player. [...] The second is that for some reason, when it's time to depart, it might not want you to leave... You heard me. I have been trapped in this cemetery 2 times already, and by trapped, we mean the iron gate is shut and will not open, even though moments earlier, it opens freely (Ghostwatcherz 2011).

This excerpt, although written and not transcribed from speech, more closely approximates an oral communication style, which "meanders around subtopics and has a conversational tone" (Fernback: 2003: 41). Without any overt signaling, the narrative flows easily from description into what may or may not be a third-person fabulate, before adopting a first-person perspective to relate what is more clearly a memorate. Even here, there is a shift from a singular to plural perspective. Blending traditional tales with personal experiences makes legends seem plausible or persuasive (McNeil 2006) and heightens their "emotional impact" (Dégh 1969: 78). In this case, the two are blended to such an extent that it is unclear which is which, whereas in the 'Damned Connecticut' excerpt they are distinct. Rather than privileging one of these styles over the other, the web forum medium seems equally suitable for either oral or textual styles of communication depending, perhaps, on the preferences of the user. In this respect, the web might be less deterministic than other mediums, giving individuals greater freedom of expression.

Another area to consider is the extent to which the internet facilitates continuity in legends as they are retold. An intrinsic dimension of oral exchanges is for individuals to pass on a story they have heard, or an encounter that they have experienced, to others. To this end, as McNeill has pointed out, "borrowing and copying have always been regular methods of recreation in folk transmission" (2015:133). Since the internet allows for replicating materials with perfect fidelity (Baym 2010), we might expect to see more users simply copy and paste legends - in whole or in part - relative to oral exchanges. As it turns out, however, this was rarely the case in the forums I investigated. Several obscure websites copied material from an old directory of haunted places called theshadowlands.net, which has not been updated for many years. Also, on one occasion, I encountered a full legend summary that consisted almost entirely of material copied and pasted from another source regarding the melon heads legend. ${ }^{2}$ Much more frequent were shorter quotes, ranging from a couple sentences to several paragraphs in length, from other sources. For example, one narrative summarizing the melon heads legends borrows heavily and verbatim from Wikipedia throughout its duration (Ackerman 2014). 
Another example can be found in a narrative summarizing the allegedly haunted 'Concord's Colonial Inn' in Massachusetts:

While no one can say for certain if a ghost haunts the Colonial Inn, many guests of Room 24 have told spooky tales of their stay at the inn. The stories began with newlywed couple M.P. and Judith Fellenz from Highland Falls, New York. They checked in to Room 24 of the inn for their honeymoon in 1966. It wasn't until two weeks later when the innkeeper at the time received the following letter from Judith [...] (Sutera 2015)

This narrative begins with the author paraphrasing a well-known legend, apparently in their own words, before going on to quote a letter at length. No source is credited for the letter, but the same text appears in numerous other retellings of this legend. ${ }^{3}$ Interestingly enough, it is nontextual components that seem most frequently copied without direct modification. Pasted images, embedded videos, and sometimes audio-recordings taken from other sources - often without attribution—are readily apparent across legend websites. ${ }^{4}$

$<$ Figure 2>

With this pattern, again, we see the ramifications of this hybrid communication method. As Peck concluded regarding online Slender Man legends, the internet "encourage[es] imitation and personalization while also allowing perfect replication" (2015: 334). Individual legendtellers have greater opportunity to simply copy prior accounts and, on occasion, some of them do just that. Yet, the appeal of these exchanges is generally not fulfilled through simple copying alone. Whether textual or multimedia, in these situations the copied material does not usually replace an original retelling. Instead, it accompanies original text provided by the poster. In this way, consistent with McNeill's (2015) observations regarding the nature of borrowing and copying, it is framed with novel material and serves as a resource that legend-tellers can draw on in their own, original retellings. However, the parts that they do borrow can indeed be perfectly replicated when copied, establishing a convincing lineage for the legend. This also somewhat confuses telling a legend with showing a legend — with ostension (Dégh and Vázsonyi 1983) —in that parts of an earlier legend narrative are directly presented rather than imperfectly represented. This hybrid narrative performance functions therefore as a sort of 'meta-ostension,' a potentially infinite regress wherein legend accounts show previous legends which, themselves, show still prior material. This device serves to further anchor the novel material within previous accounts while also providing the opportunity to interpret and extend these.

Rather than faithfully duplicating existing legends, online legend-tellers thus express considerable creativity and variability in their narratives while simultaneously repeating parts of prior accounts. This can result in detailed, elaborate retellings but sometimes, instead, only fragments of a legend are reiterated in the narrative. For example, a YouTube video of an investigation at the Daniel Benton Homestead - an allegedly haunted, historic house in Connecticut - similarly begins with a summary of the legend, but it is very brief and incomplete (Pudgeman 2019). The narrator, standing in front of the house, tells the viewer where he is and that it is haunted. Then, in a variation on meta-ostension, he copies himself: a recording of his previous investigation there is spliced into the video and provides further details of the legend. The camera reveals a nighttime scene, viewed from the interior of a car as it pulls up to the house. No occupant can be seen, but we can recognize the voice of the narrator as he discusses the legend with another person. They briefly relate how smallpox allegedly killed the residents of the house who are buried on the property. This abridged background sets the scene for the 
legend-trip that immediately follows. The shot returns to the present as the narrator begins investigating the grounds of the homestead. The end of the video concludes with the narrator, presumably back at home, showing a newspaper clipping about the haunting to the camera. While he does not read the article, the shot zooms in and pans slowly across the text. He recommends that interested viewers pause the video so they can read it. This account thus blurs the distinctions between copied and original material, between memorate and fabulate, and between legend-telling and legend-tripping. The various perspectives shift back and forth and inform one another as the action unfolds. The internet, here, thus allows for a sort of meandering conversation (Fernback 2003), but it does so by merging several legend-trips and past accounts through spliced videos rather than spoken narrative alone. In other words, it amplifies the traditional characteristics of oral accounts through the provision of powerful story-telling tools while simultaneously enabling novel methods of narration.

$<$ Figure 3>

In contrast to this example, sometimes the initial legend-narration of a forum gives very little information at all. This was especially common for the 'directory' style website, which provide dedicated pages to a diverse number of legends. The entries from hauntedplaces.org offer typical examples. For instance, its page for 'Connecticut Hill Cemetery,' in Newfield, New York, consists of a mere two sentences listing some strange phenomena said to dwell here (Haunted Places n.d.[a]). There is no fabulate about how the place came to be haunted by its spirits, sasquatch, or UFOs, nor is there any memorate to bring these claims to life. Of course, missing pieces of this sort are no barrier to the legend process. Indeed, they feed it. Although there is no particular prompt to do so, the first forum post following this unsatisfactory legend narrative begins to fill in the gaps:

So the story I was told was that there once was a town that disappeared, and only a few residents had survived or got out etc... So I was very interested. Friends of mine were up for the treck up the hill. So on New Years eve or sometime during the winter we started out. I sat in the back of the truck. I noticed some white blurs a long side the truck in the woods, but that could have been the snow. We weren't going that fast. You can't actually go that fast since it is a seasonal dirt road. So we stopped at the top of the road where it T's. So we got out of the truck. I walked out [t]o the middle of the T intersection. Off to my Left was a tree line. I heard a growl. I walked back to the truck and let the others know. The driver had a large flash light and so we both walked over to the are[a] where I heard the growl. We shined the light and where the light landed again their was a growl. We couldn't see anything. There was no eye shine nothing!!! So we decided it would be better to leave. (Haunted Places n.d.[a]).

In the absence of a coherent opening legend account, it is up to the audience - to forum participants - to supply the missing narrative. Told in the dichotomous style and following other conventions of legend-tripping, such as spooky encounters and hasty retreats (Ellis 2003), this is exactly what this first post attempts to do. It includes both a brief fabulate, with some explanation for the legend's origins, and a longer memorate of encounters there. Other forum participants similarly fill in the gaps in the opening narrative, albeit in a piecemeal, halting, and collaborative fashion. In fact, it seems likely that the designers of websites like hauntedplaces.org fully expect and depend upon this sort of audience participation for the primary content of their website. Like so many other web services, such as YouTube or Facebook, they offer little content of their own, but instead provide easy mechanisms for users to 
produce it for them (Jenkins 2006). The website, consequently, enables a vernacular exchange that blurs distinctions between narrator and audience while both recording and crystallizing the legend-process.

\section{$<$ Figure 4>}

The functions of forum legend-narratives are even more clear on websites where there is no separate opening narration of a legend, but only a forum dedicated to one. These sometimes begin with a spontaneous post offering an overview of a legend a forum user has heard about or investigated. More often, however, these forums might simply jump right into the action of discussion: particularly, by asking other users for information. One typical example comes from a discussion forum dedicated to the allegedly haunted Gunntown Cemetery. The first posts reads "I have seen several youtube shows of videos and pics of investigations at gunntown cem. in naugatuck, ct. How watched is the cemetery and how is it watched (ex. nosy neighbors?)" (Ghostvillage 2008). Unlike many other websites, this bypasses an opening summary entirely. It begins instead with a question that reveals very little about the legend associated with this site. Reading this question, it is unclear what might even be legendary about the cemetery that might warrant 'investigations.' Instead of supplying information, the post requests it. This request invites forum participants immediately into discussion and requires that they offer sketches of the legend themselves rather than react to one provided by a primary narration. Interestingly, this opening also reveals an example of the hybridized nature of the internet (Blank 2018) and its effects on the legend process. In this case, apparently, a YouTube video inspired the user to start a discussion in a separate forum with the intention of ultimately gaining information to guide a visit to the physical site. It would not be surprising if they ultimately posted the results of their visit back onto the web.

\section{$\underline{\text { Legend Discussion }}$}

An integral element of legends is discussion: "Unlike tales, which usually are separated from normal conversation and attended without interruption, legends must be seen as part of a communal event, in which the audience's role is as important as the narrator's. [...] In other words, legends are not folk literature but folk behavior" (Ellis 2001: 10). Thus far I have examined legend narratives alone with little consideration of the audience reading (or viewing) these, except where the legend was largely provided by that audience itself. Not surprisingly however, given the interactive nature of the internet (Baym 2010), audience participation is indeed present in online forums and an important component of the whole. Equally unsurprising is the fact that the medium again has a significant effect on exactly how this participation occurs. The legends I examined in the previous section are unbroken narratives. Audiences cannot interrupt the text or the video to ask questions, make comments, or offer challenges in real time. Instead, they can only post their contributions in the forum portion of the website that spatially and temporally follows the narration. Although the author of the lead narrative might also contribute in the comments section, this nonetheless means that these contributions cannot affect the original narration nor can they punctuate it. Except in the rare situation where a narrator might actually edit their account in response to subsequent user comments, the legend narrative found in most forums is consequently a monologue rather than the dialogue found in oral communication. Taken on its own, it is somewhat more like the legend summaries found in a published book, where readers cannot interrupt or influence the author's words. 
Nonetheless, discussion of a sort does occur. Indeed, since early in their history, "an expectation had developed that blogs would offer the chance for audience members to post their own "comments"" (Howard 2008b: 195). This is true on many legend sites as well. However, discussion must follow after the opening narrative, if one is present, in a section reserved for these user comments. This results in a strange structure, where legend and discussion are artificially separated from each other by website architecture. Taken in their entirety however, these elements still constitute a sort of dialogue - a folk behavior rather than a story (Ellis 2003) - albeit one with characteristics distinct from strictly oral modes. Returning to a Gunntown forum with this bifurcated structure to illustrate, we see a lengthy and rich discussion consisting entirely of users directing their comments to one another and to the preceding legend narrative (Bendici 2009). Like an organic conversation, it consists of a range of perspectives and comment types. Some posts express interest and enthusiasm, others ask questions, and a considerable number entertain debate over whether the cemetery is haunted. For example, one critical post states, "umm ya NO this is NOT haunted! It's just a tiny little cemetery that was used for a couple families [.]" Another post replies to it, "Are you nuts? The Warrens certified this place is haunted many years ago. I've seen myself what happens in this place at night [.]" 5

This sort of debate is integral to the legend process and web platforms include built-in elements that facilitate or encourage just that. Many sites, especially social media ones, include 'thumbs up' or 'thumbs down' features which act "as a communal barometer of folk approval and appreciation" (Blank 2018:2). A pronounced instance of this for legend sites is on hauntedplaces.org. Each individual page is devoted to a separate legendary place and begins with a brief legend narrative. As with other sites, this is followed by a forum section for user discussion, but between the narrative and the forum is a section titled, "Rate this Haunted Place." Text asks the user, "What do you think? Is this place really haunted?" It then directs them to click on either a thumbs up or down button to indicate their opinion. The entry for Gunntown Cemetery shows that $88 \%$ of voters believe it haunted (Haunted Places n.d.[b]). Although users can offer more elaborate perspectives in the forum section, it is noteworthy that this feature primes that discussion by encouraging debate without nuance. In the vernacular tradition, people's perceptions of legends do not fit so neatly into this "seemingly rigid dichotomy" of belief versus disbelief (Ellis 2003: 44). Rather, they might be ambivalent, unsure, or nearly anything else. They can even express "a confluence of suspending disbelief, pretend play, and make-believe" (Kinsella 2011: 18). Yet, this binary web feature forces users into unnatural, competing belief or disbelief camps. This reflects the unfortunate potential of the web to polarize people and intensify discord: encouraging them to commit to simplified 'sides' and engage in virtual conflict. Anonymous, protected from physical reprisal, and buffered from subtle social cues of displeasure, there are few mechanisms present to maintain civility or at least good-faith discussion when disagreements arise (Febriana and Fajrianthi 2019).

Considering web forums' asynchronicity and relative permanence (Baym 2010) reveals further ways in which legend-discussion differs from oral discussion. For the latter, participants must be present at the same time and, once they have spoken, their words are gone forever. One could of course try to remember these interactions or record them but, as noted earlier, this introduces the fallibility of memory or a new communication method (e.g. audio recording) rather than extending the initial oral interaction. Something similar happens in synchronous web interactions, like Zoom or chatrooms (Blank 2018). With forums, however, recorded text is relatively enduring, potentially persisting for many years for others to view (Montero and Stokols 2003). To the extent that forums content is persistent, it is more like text in a book than 
an oral interaction. Unlike a book though, forums maintain a high degree of interactivity online for however long they endure. During this time, "[u]nlike static texts, they are always generating their shared meanings" (Howard 2008b: 199). This means that a single legend discussion can conceivably continue for many years online, instead of the relatively few minutes of an oral discussion. In the aforementioned hauntedplaces.org forum for Gunntown, the first comment was posted in 2015 and the most recent in 2019 (Haunted Places n.d.[b]. One of the melon head forums includes comments ranging from 2008 to 2016 (Bendici 2010). If legends reflect people's concerns and change over time as these concerns change (Brunvand 1981), the forum would be an ideal resource for charting such developments. In this way, web forums are not simply texts that can be analyzed for content. Instead, they are extended legend-telling sessions that have been crystalized - for a time - by the internet, until the next forum user posts a new comment and reinvigorates the discussion.

Just as forum posters cannot know when another user will read their comments - perhaps tomorrow or perhaps years from now - neither can they know for sure whom will read them. The internet's potential reach is much greater than that of in-person, oral communication. It provides "persistent network locations [which] offer individuals the chance to repeatedly locate and participate with each other, without full recourse to the geography necessary in real-world communities [...]" (Howard 2008b: 199). Many more people across a wider area-conceivably across the planet - can interact at the same time or asynchronously. In practice, however, this rarely seemed to be the case with the legends I analyzed. For example, one web article provided an introduction to some of the local legends about a street in Connecticut called 'Downs Road' (Schurman 2012). Most of Downs Road is relatively rural and remote. Some houses are scattered along its length, which runs through the towns of Bethany and Hamden. One long stretch that would otherwise connect the towns, however, is blocked off to traffic and is largely abandoned, used only by the local water company, hikers, and legend-trippers. A discussion forum follows the article itself, consistent with other websites discussed above, and here we see some interesting examples of the limitations of reach.

\section{$<$ Figure 5>}

First, it is difficult to know for sure whom anonymous posters to internet forums are, but few of them gave any indication that they were from places far away from the legend's setting. Most seemed, to the contrary, to delight in their own proximity to it. The first sentence of forumusers contributions tended to emphasize their local connection. For example:

"As a 23-year resident (my husband has lived there his entire life of Downs Road) [...]"

"I was a 'cop' in Woodbridge [a nearby town] for 25 years and heard the Downs Rd. story many times"

"When I first moved to Bethany [...]" (Schurman 2012)

Comments like these were commonplace. A considerable number of people took pride in having some close connection to Downs Road and, therefore, some special connection to its legends. This included living near the site currently or previously, but also included having friends who live nearby or having a family connection to the area as the following examples illustrate:

"I have been down Downs rd numerous times to go to my friends house."

"I grew up in Bethany and am very curious to say the le[a]st about these stories." 
"My grandmother lived on Downs road all her life."

"Do any of you know the history of the Downs family after which the road was named?

[...] They're ancestors of mine[.]" (Schurman 2012)

The apparently limited geographic reach of forums like this might be due to the fact that my data are limited to specific places. Except for truly famous cases, their appeal is generally limited by their locality, whereas legends less bound to specific places might spread more widely (e.g. Fernback 2003, Soltero 2016). Whatever the reason, it is interesting to note that something which is a technological possible — vast reach-remains largely unrealized due to human factors like local interest. Instead, the internet reinforces existing, geographically bounded communities rather than surpassing the traditional bounds of physicality.

Nonetheless, the great reach of the internet can yield a number of other surprising outcomes in real life. It blurs distinctions between public and private space since, for example, many people can have personal conversations at once, but they do not necessarily know with whom they are conversing. Forums can especially aggravate this problem. Not only are the other current users unknown, but one cannot read their body language. Worse, they do not know who might join the conversation in the future and whether those people will be sympathetic or not to something they have already posted to the emerging conversation. Web forums can thus provide an accessible place for like-minded people to form a virtual community (Rheingold 1994), but they can also provide easy access to less sympathetic people who can actually cause problems for that community (Debies-Carl 2015).

In the case of the Downs Road forum, discussed above, the discussion quickly turned from enthusiastic sharing and discussion of the legend to heated argument. Some posters disagreed with the possibility of supernatural entities at Downs Road:

That's so funny about the supposed sightings of the "monster". My husband grew up on Downs Road, and wandered the woods and water company property his entire life, and never once saw anything - not even a bear. (Schurman 2012)

Disagreement is part of the discussion process, but more incensed conflict can be problematic. One poster, who also apparently lived in the area, did not take kindly to the initial article drawing what they saw as problematic attention to their neighborhood:

I have to say that we are not very happy with the descriptions of "eerie" or "spooky" when it refers to our front yard. We are very happy with the peaceful wooded nature of our neighborhood and would appreciate it being respected. We have lived here for over twenty years and can honestly say that the only scary things on Downs Road are the people who come looking for scary things [...] My exact point is that these stories bring exactly the wrong people to our neighborhood at all the wrong hours and for all the wrong reasons. (Schurman 2012) ${ }^{6}$

Comments like these seemed to dampen the emerging consensus and threatened to entirely derail the ongoing conversation. A large portion of the forum became an argument between people on different sides regarding whether the legend was problematic for the town or something exciting that enriches its sense of place.

Traditionally. legends are shared among people with similar backgrounds and concerns: they "circulate among [...] groups of people who have something in common" (Kinsella 2011: 7). In this way, they can produce social cohesion and reinforce a sense of community. The 
internet complicates these matters. In the above case, we see how a local connection breeds especial interest in a legend. In this situation, however, that interest did not simply produce solidarity and shared community. We actually see two sorts of community threatened by the accessibility of the internet that allows 'outsiders' into its midst. First, there is the virtual community of legend enthusiasts. Critics or opponents of the legend and legend-tripping can easily find a forum and intrude upon it to voice their displeasure. In doing so, they might shatter the feeling of sympathetic interest and shared identity. Conversely, flipping the situation around, the internet makes it easy to intrude upon individuals' actual neighborhoods. Some of the aforementioned critics were opposed to legend-tripping specifically when it occurs in their backyards and attracts potentially problematic adventurers. Here, it is not virtual community at stake, but physical community. Thus, while the characteristics of computer-mediated communication make it easier to create a sense of community, ironically, they also provide the tools to more readily attack it. For community in either sense, the function of the internet seems more to cement group boundaries than to expand them to include greater diversity of opinion or geography.

\section{Conclusions}

The internet provides a potent mechanism for the dissemination of legends but, as indicated by this investigation its novel characteristics and hybrid nature ensure that it affects that dissemination in complex and sometimes unexpected ways. First, in some capacities, the internet subverts some of the traditional characteristics of the legend-telling process. For example, we saw how it can introduce a strangely asynchronous form of discussion or reduce audience participation during legend-narration. Second, paradoxically, other characteristics of the internet actually reinforce or valorize traditional elements. This was the case, for instance, through its provision of tools and materials for individuals to creatively tell — or embellish — their legends creatively. Third, and perhaps most surprisingly, sometimes the internet has no effect at all even in areas where we might expect the most significant effects. The finding that best illustrates this was the failure of the internet to open up interest in local legends to a broader, perhaps even global, audience. Instead, the inherent appeal of legends remained geographically bounded, regardless of technological capacities to the contrary.

Interestingly, the content and some dimensions of the form of online legends themselves are nonetheless similar to oral equivalents. They include similar traditional components - such as accounts of alleged past happenings, warnings, threats to morals and values, and incomplete and dichotomous structures. Online legends that include a forum section mirror other standard components of the legend process. They serve as a place for people to investigate and discuss matters of shared concern. Here, virtually, people can debate legends, ask questions, argue, offer their own experiences, and interpolate legend content. On account of these many similarities, we can safely conclude that online legends largely fill a similar place in society as legends always have. Overall, this portion of the analysis supports Blank's observation that, "many of the texts and performative dynamics that folklorists have traditionally identified in face-to-face contexts appear to be surfacing through technology in very similar meaningful ways as their oral and corporeal precedents" (2012: 12).

However, reconciling these two realities presents challenges to both legend participants and researchers. If legends themselves occupy the same social location they always have, how is 
that position affected by the unique properties of the net? There were a number of novel characteristics of online legends that complicate the general function of legend-telling. For example, if legends exist in part as a means for like-minded individuals to discuss shared concerns (Ellis 2003), that capacity is challenged by online legends' more rigorously dichotomous structure, asynchronous discussion, and a fierce polarization of debate. Likewise, the community-forming function of legends (Kinsella 2011) is jeopardized online, where it is easy for 'outsiders' to introduce conflict into social consensus-making. Further research is necessary to understand these subtleties and to determine the extent to which they exist on other web platforms beyond forums, like Facebook or Twitter.

Another matter to consider is what, exactly, causes those differences that were observed between online and oral legend traditions. In part, of course, these differences were enabled by the distinctive characteristics of the internet: its high degree of interactivity, capacity for anonymity, and so on. Yet, it would be a mistake to take a determinist approach and assume that these characteristics simply caused the observable differences. Again, some possibilities that the internet enables nonetheless did not actually occur. For example, the ability to perfectly copy and paste legends or, more darkly, the possibility to expand the diversity and reach of virtual communities. These largely remained unrealized in their potential. Instead, consistent with its hybrid nature (Howard 2008b) we can conclude that the role of the internet is much more complex. It enables novel means of communication, but does not require them. It modifies the character, content, and perhaps even intent of communication, but it does so in interaction with traditional means and goals.

We saw, for instance, how the asynchronous character of web forums alters the nature of discussion that takes place there, but that discussion does nonetheless occur. Previous researchers have noted how the internet can accelerate the legend process as messages and discourse are capable of moving at light speed around the globe (Boyer 2013, Soltero 2016). Conversely, the findings of the current paper also illustrate how-somewhat paradoxically - the internet can also slow this process down. Online, people can exchange information rapidly all over the world, but in some online contexts like forums, their contributions can instead linger for a long time. Others can view that content days or years later and also make their own contribution to the extended discussion. Forums can even serve as a repository for defunct legends that have lost their popular appeal. There, they can lay dormant until their messages spark the interest of some passing visitor again who can "necro" the hibernating legend by responding to the long-silent thread and reawakening discourse regarding its claims. Consequently, we are left with online folklore practices that are neither entirely novel nor entirely traditional. As the internet and related technologies continue to expand in terms of both their functionality and their increasing reach into other areas of our lives, we can expect to see more of this dynamic equilibrium.

Rather than simply affecting or being affected by vernacular processes, the web is both bellwether and facilitator of broader social changes. For example, observers have noted that global society is increasingly characterized by a blurring of creator/consumer boundaries that results in a more participatory co-creation of culture (Jenkins 2006). Others have noted the greater significance of computer-mediated technologies in every aspect of human life, including the perpetuation of that culture (Reed 2019). It is therefore not surprising to find similar changes in vernacular culture. In the current case, we see this through the use of the internet to share, discuss, and co-create legends. Interestingly, these changes mark something of a return to earlier eras before there was an artificial divide between producers and consumers - that is, between 
narrators and audiences - which vernacular life had always blurred before the ascendancy of mass media and consumer culture (McNeill 2015). Ironically, then, the type of change facilitated by modern technology is partly enabling a return to the past while simultaneously carrying us further away from it.

Just as we live in an "increasingly media-saturated society" (Fernback 2003: 43) so are we living in a society where people spend increasing amounts of time online. The internet will continue to be an important medium for legend discourse. Thus, it remains "imperative that we recognize that while the cultural milieu undergoes recalibration at a breakneck pace, the traditional genres and expressive dynamics long chronicled by folklorists continue to thrive in hybridized expressive materials" (Blank 2018: 6). Digital media like the internet have become a taken-for-granted part of everyday life to such an extent that that they might even be considered "mundane, boring, and routine" (Baym 2010: 5). As we have seen, their reach has extended even beyond the banal world into the realm of the fantastic. As we have also seen, their transformative influence in the worlds they touch - mundane or spectacular - are anything but banal. Indeed, they are the stuff of legend.

\section{References}

Ackerman, Micah. 2014. "The Melon Heads: Creepy Urban Legend or Real Life Horror?" http://www.micahackerman.com/blog/the-melon-heads-creepy-urban-legend-or-real-life-horror, accessed April 22, 2018.

Baym, Nancy K. 2010. Personal Connections in the Digital Age. Malden, MA: Polity.

Bendici, Ray. 2009. "Gunntown Cemetery, Naugatuck.” http://www.damnedct.com/gunntowncemetery-naugatuck, accessed January 1, 2018.

-----. 2010. “The Melon Heads.” http://www.damnedct.com/the-melon-heads, accessed April 22, 2018.

Blank, Trevor. 2012. Folk Culture in the Digital Age: The Emergent Dynamic of Human Interaction. Boulder, CO: Utah State University Press.

-----. 2015. "Faux Your Entertainment: Amazon.com Product Reviews as a Locus of Digital Performance.” Journal of American Folklore 128 (509):286-97.

https://www.jstor.org/stable/10.5406/jamerfolk.128.509.0286

----. 2018. "Folklore and the Internet: The Challenge of an Ephemeral Landscape." Humanities

7(2):1-8. https://www.mdpi.com/2076-0787/7/2/50

Boyer, Tina Marie. 2013. "The Anatomy of a Monster: The Case of Slender Man." Preternature 2(2):240-261. https://www.jstor.org/stable/10.5325/preternature.2.2.0240

Brunvand, Jan Harold.1981. The Vanishing Hitchhiker: American Urban Legends and their Meanings. New York: Norton.

Cohen, Jeffrey. 1996. Monster Theory. Minneapolis: University of Minnesota Press.

CT Boom. 2017. “Is this Connecticut's Most Haunted Street?” http://ctboom.com/is-thisconnecticuts-most-haunted-street/, accessed April 22, 2018. 
Debies-Carl, Jeffrey S. 2015. "Print is Dead: The Promise and Peril of Digital Media for Subcultural Resistance.” Journal of Contemporary Ethnography 44 (6): 679-708.

-2017. "Pizzagate and Beyond: Using Social Research to Understand Conspiracy Legends." Skeptical Inquirer 41 (6): 34-37.Dégh. Linda. 1969. "The Haunted Bridges Near Avon and Danville and their Role in Legend Formation." Indiana Folklore 2(1):54-89.

Dégh. Linda. 1969. "The Haunted Bridges Near Avon and Danville and their Role in Legend Formation." Indiana Folklore 2(1):54-89.

-----. 1971. 'The 'Belief Legend' in Modern Society: Form, Function, and Relationship to Other Genres.” Pp.55 - 68 in Wayland Hand (ed.) American Folk Legend: A Symposium. Los Angeles: University of California Press.

-----. 2001. Legend and Belief: Dialectics of a Folklore Genre. Bloomington, IN: Indiana University Press.

Dégh, Linda and Andrew Vázsonyi. 1983. "Does the Word 'Dog' Bite? Ostensive Action: A Means of Legend-Telling.” Journal of Folklore Research 20(1):5-34.

https://www.jstor.org/stable/3814298

Ellis, Bill. 2003. Aliens, Ghosts, and Cults: Legends We Live. Jackson, MS: University Press of Mississippi.

Fear Channel. 2013. "The Legend of the Melonheads - Urban Legend." https://www.youtube.com/watch?v=OTg0u2CU1Ns, accessed April 22, 2018.

Febriana, S.K.T. and Fajrianthi. 2019. “Cyber Incivility Perpetrator: The Influence of Dissociative Anonymity, Invisibility, Asychronicity, and Dissociative Imagination." Journal of Physics: Conference Series 1175:1-8. https://iopscience.iop.org/article/10.1088/1742$\underline{6596 / 1175 / 1 / 012238 / \text { meta }}$

Fernback, Jan. 2003. "Legends on the Net: An Examination of Computer Mediated Communication as a Locus of Oral Culture." New Media \& Society 5(1):29-45. https://journals.sagepub.com/doi/abs/10.1177/1461444803005001902

Freedom's Way National Heritage Area. n.d. "A Haunting We Will Go." http://freedomsway.org/haunting-will-go/, accessed April 14, 2020.

Ghostvillage. 2008. "Gunntown Cemetery."

https://www.ghostvillage.com/ghostcommunity/index.php?showtopic=23664, accessed February 3, 2020.

Ghostwatcherz. 2011. "Haunted Gunntown Cemetery - Naugatuck, CT."

http://www.ghostwatcherz.com/guntown-cemetery-naugatuck-ct/, accessed January 20, 2018.

Hall, Gary. 1973. "The Big Tunnel: Legends and Legend-Telling.” Indiana Folklore 6(2):13973.

Haunted Places. n.d.(a). "Connecticut Hill Cemetery." https://www.hauntedplaces.org/item/connecticut-hill-cemetery/, accessed July 8, 2018.

-----. n.d.(b). "Gunntown Cemetery." https://www.hauntedplaces.org/item/gunntown-cemetery/, April 16, 2020. 
Howard, Robert G. 2005. "Toward a Theory of the World Wide Web: The Case for Pet Cloning." Journal of Folklore Research 42(3): 323-60. https://www.jstor.org/stable/3814919

-----. 2008a. Tags and Burners, Cycles and Networks: Folklore in the Telectronic Age. Journal of Folklore Research 27(3): 179-90. https://www.jstor.org/stable/3814251

-----. 2008b. "Electronic Hybridity: The Persistent Processes of the Vernacular Web." Journal of American Folklore 121(480):192-218. https://www.jstor.org/stable/20487596

Jenkins, Henry. 2006. Convergence Culture: Where Old and New Media Collide. New York: New York University Press.

Kibby, Marjorie. 2005. "Email Forwardables: Folklore in the Age of the Internet." New Media \& Society 7(6): 770-90. https://journals.sagepub.com/doi/abs/10.1177/1461444805058161

Kinsella, Michael. 2011. Legend-Tripping Online: Supernatural Folklore and the Search for Ong's Hat. Jackson, MS: University Press of Mississippi.

Know Your Meme. n.d. "Necro Posting." https://knowyourmeme.com/memes/necro-posting, April 2, 2020.

Kozinets, Robert. 2010. Netnography: Doing Ethnographic Research Online. Thousand Oaks, CA: Sage.

Langlois, Janet L. 2014. "They All See Dead People_-But We (Do)n't Want to Tell You About It: On Legend Gathering in Real and Cyberspace." New Directions in Folklore 12(1): 5-56. https://scholarworks.iu.edu/journals/index.php/ndif/article/view/12768

Lincoln, Yvonna S. and Egon G. Guba. 1985. Naturalistic inquiry. Beverly Hills, CA: Sage.

McNeill, Lynne S. 2006. "Contemporary Ghost Hunting and the Relationship Between Proof and Experience.” Contemporary Legend 9:96-110.

----. 2009. "The End of the Internet: A Folk Response to the Provision of Infinite Choice." Pp. 80-97 in Trevor J. Blank (ed.), Folklore and the Internet: Vernacular Expression in a Digital World. Logan: Utah State University Press.

-----. 2015. “Twihards, Buffistas, and Vampire Fanlore.” Pp.126-145 in Jeannie Banks Thomas (ed.), Putting the Supernatural in its Place: Folklore, the Hypermodern, and the Ethereal. Salt Lake City: University of Utah Press.

Mehrpour, Omid and Mahmood Sadeghi. 2020. "Toll of acute methanol poisoning for preventing COVID-19." Archives of Toxicology 94:2259-2260. https://link.springer.com/content/pdf/10.1007/s00204-020-02795-2.pdf

Montero, Maria, and Daniel Stokols. 2003. "Psychology and the Internet: A Social Ecological Analysis." Cyberpsychology and Behavior 6(1):59-72. https://www.liebertpub.com/doi/abs/10.1089/109493103321167974

Muise, Peter. 2015a. "Melonheads Part 1: A Trip Down Dracula Drive." http://newenglandfolklore.blogspot.com/2015/08/melonheads-part-i-trip-down-dracula.html, accessed April 22, 2018.

-----. 2015b. "Melonheads Part II: Why So Many Big Heads?"

http://newenglandfolklore.blogspot.com/2015/08/melonheads-part-ii-why-so-many-bigheads.html, accessed April 22, 2018. 
Peck, Andrew. 2015. "Tall, Dark, and Loathsome: The Emergence of a Legend Cycle in the Digital Age.” Journal of American Folklore 128(509):333-48.

https://www.jstor.org/stable/10.5406/jamerfolk.128.509.0333

Pudgeman. 2019. "GHOST HUNT!!-Benton Homestead.” https://www.youtube.com/watch?v=KlbZdZV36YM, accessed March 20, 2019.

Raufman, Ravit and Rachel Ben-Cnaan. 2009. "Red Riding Hood: Text, Hypertext, and Context in an Israeli Nationalistic Internet Forum.” Journal of Folklore Research 16(1):43-66. https://www.jstor.org/stable/40206939

Reed, T.V. 2019. Digitized Lives: Culture, Power and Social Change in the Internet Era. NY: Routledge.

Rheingold. Howard. 1994. The Virtual Community: Finding Connection in a Computerized World. London: Secker and Warburg.

Schurman, Kathleen. 2012. "There are Monsters Among Us - On Downs Road, Anyways." http://patch.com/connecticut/bethwood/there-are-monsters-among-us-on-downs-road-anyways, accessed April 21, 2016.

Soltero, Gonzalo. 2016. “The Mexican Transmission of 'Lights Out!'” Journal of Folklore Research 53(3):115-35. https://www.jstor.org/stable/10.2979/jfolkrese.53.3.01

Sutera, Marissa. 2015. "A Night of History at Concord's Colonial Inn." https://www.littlethingstravel.com/night-of-history-at-concords-colonial-inn/, accessed May 7, 2017.

Thigpen, Kenneth. 1971. "Adolescent Legends in Brown County: A Survey." Indiana Folklore 4(2): 141-215.

Tolbert, Jeffrey A. 2013. "The Sort of Story that has You Covering Your Mirrors: The Case of Slender Man." Semiotic Review 2 (November): no pagination.

https://www.semioticreview.com/ojs/index.php/sr/article/view/19

Tucker, Elizabeth. 2007. Haunted Halls: Ghostlore of American College Campuses. Jackson, Mississippi: University Press of Mississippi.

-----. "'There's an App for That': Ghost Hunting with Smartphones." Children's Folklore Review 38:27-38. https://scholarworks.iu.edu/journals/index.php/cfr/article/view/25074

Walker, Jessie. 2014. The United States of Paranoia: A Conspiracy Theory. New York: Harper.

JEFFREY S. DEBIES-CARL is Associate Professor of Sociology in the Department of Psychology and Sociology at the University of New Haven. His research examines the cultural significance of physical and virtual environments, spanning such diverse topics as countercultural enclaves, legendary places, and local microbreweries. He is the author of Punk Rock and the Politics of Place: Building a Better Tomorrow (Routledge, 2014). 


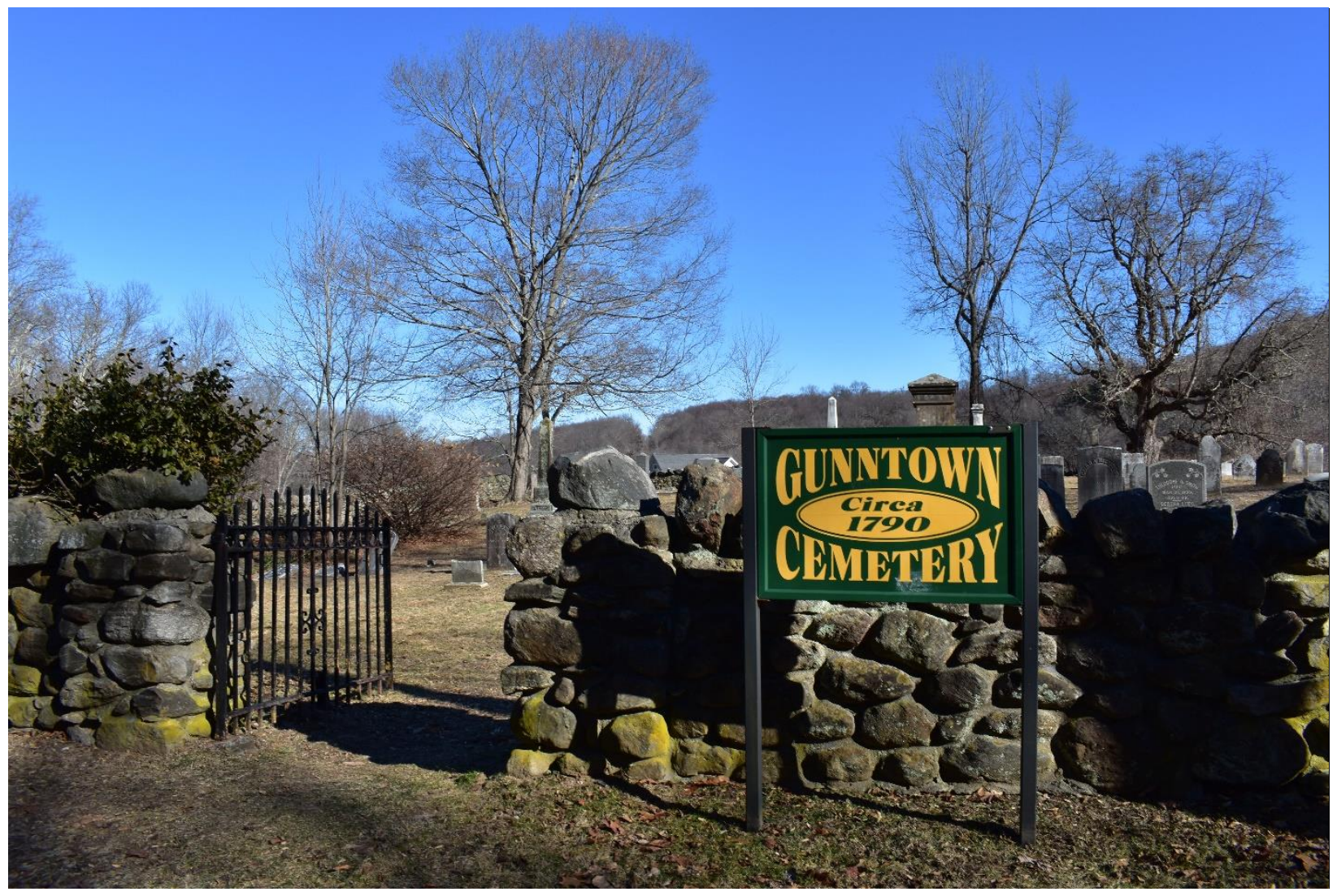

Figure 1: Gunntown Cemetery (Naugatuck, CT): A quiet graveyard with vigorous online discussion (Photo by the author) 


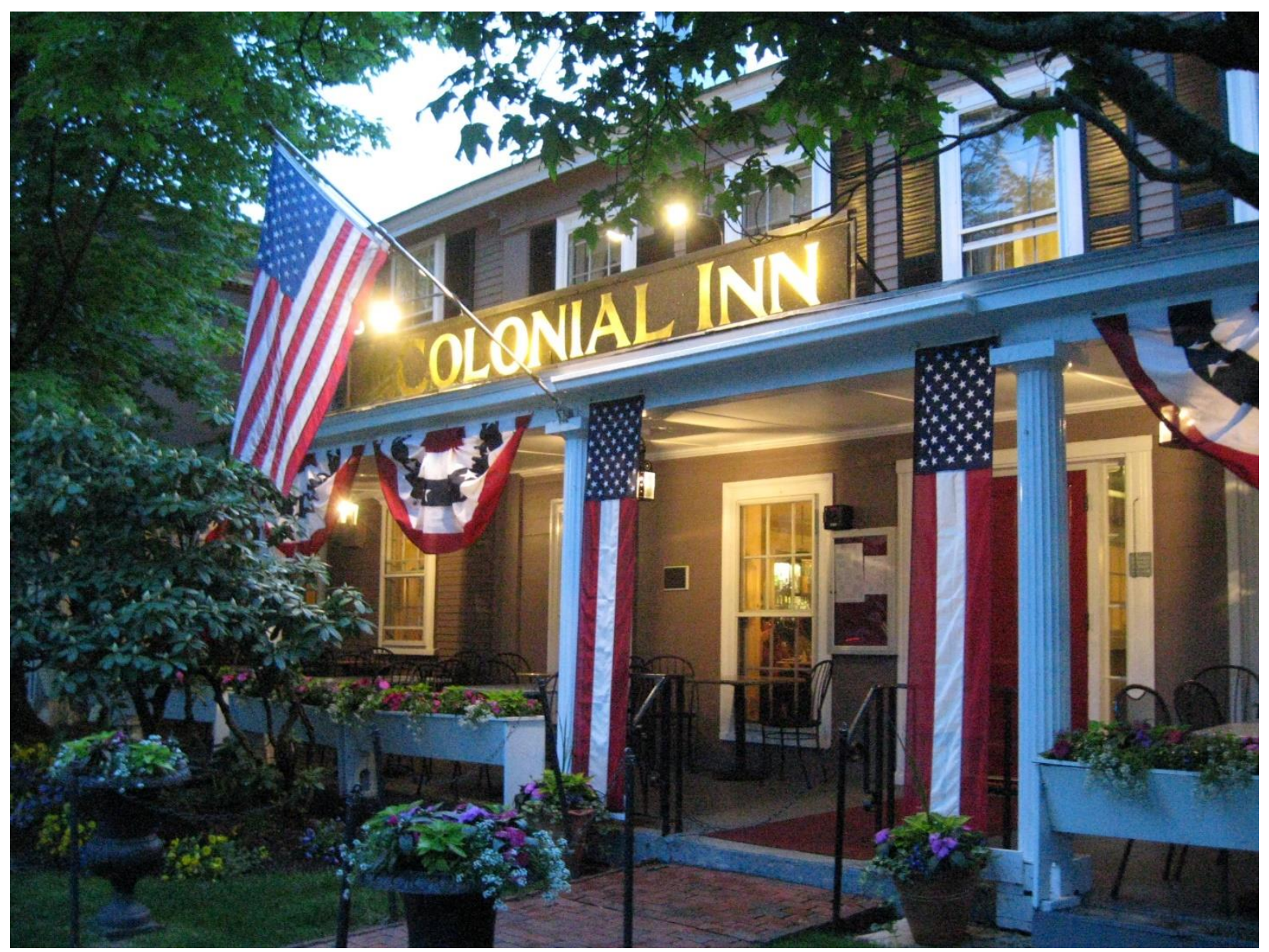

Figure 2: Concord's Colonial Inn (Concord, MA): Portions of its legend are faithfully reproduced online (Photo by the author) 


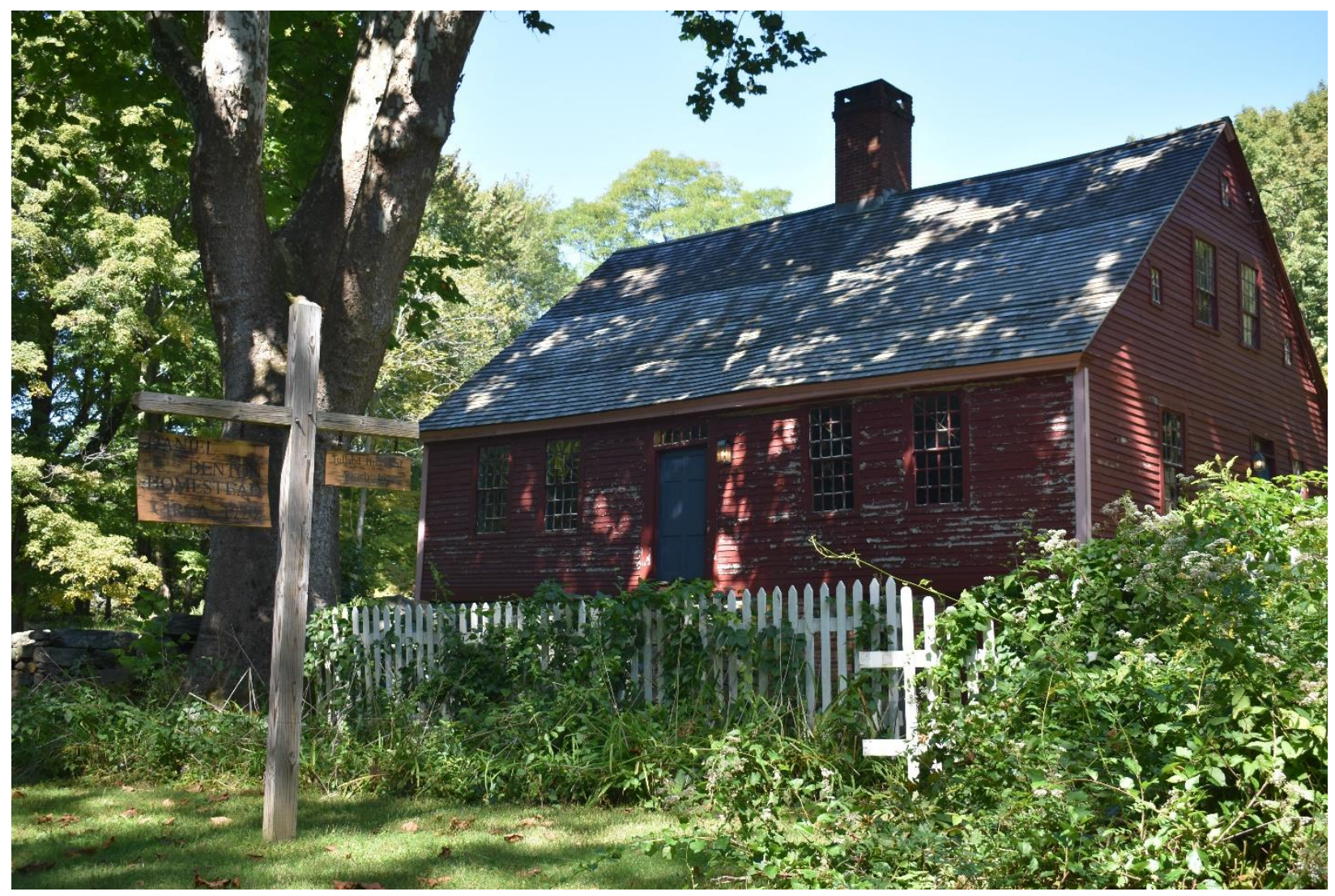

Figure 3: Daniel Benton Homestead (Tolland, CT): A site for meta-ostension (Photo by the author) 


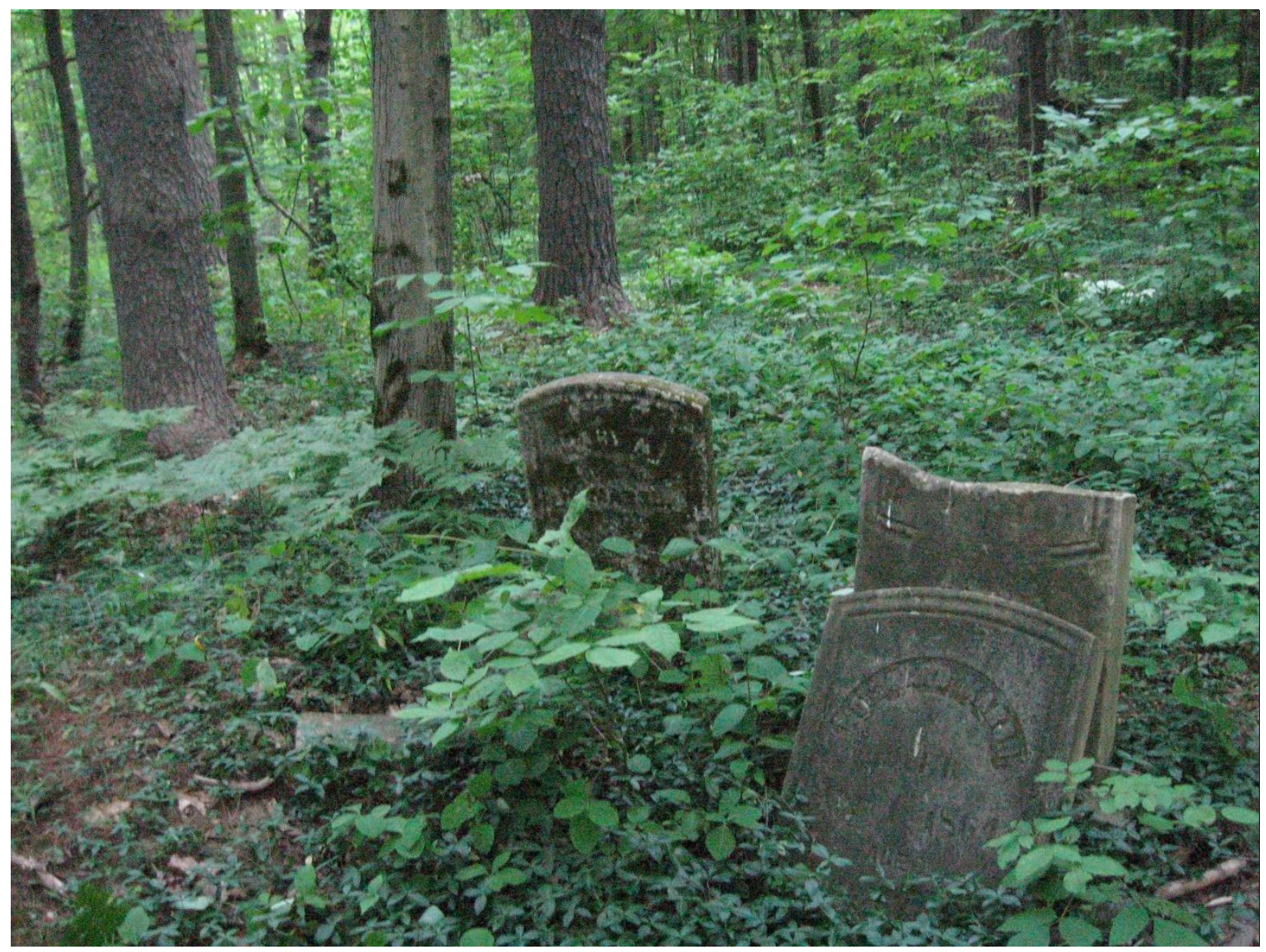

Figure 4: Connecticut Hill Cemetery (Newfield, NY): Here, vague legends require inspire interpolation (Photo by the author) 


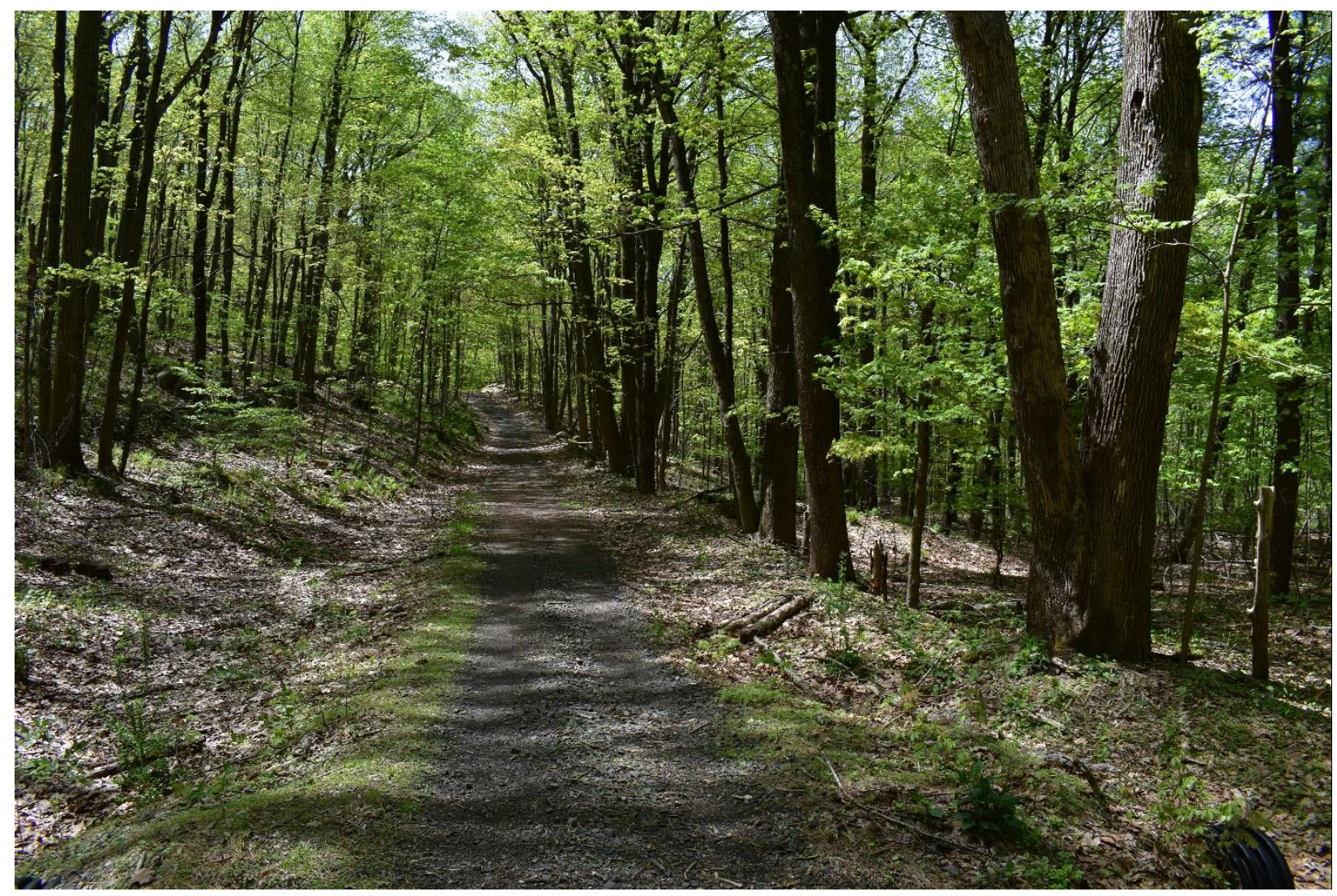

Figure 5: Downs Road (Hamden and Bethany, CT): A place for legend-tripping or a private neighborhood? (Photo by the author)

\footnotetext{
${ }^{1}$ Digital ethics are an uncertain and continuously evolving arena. In addition to Kozinets (2010), interested readers should refer to Blank (2007) and Langlois (2014).

${ }^{2}$ I have not cited this exception to protect the poster since, although they claims they received the copied material in an email, I also found it in a copyrighted book.

${ }^{3}$ For example, this same text is repeated at Freedom's Way National Heritage Area. (n.d.).

${ }^{4}$ Since these run the risk of copyright violation, I have not cited specific offenders, but interested readers should have no trouble finding examples online.

${ }^{5}$ Referring to Ed and Lorraine Warren who became both famous and controversial for their popularization of questionable cases and role in turning these cases into profitable films like The Amityville Horror and The Conjuring.

${ }^{6}$ I have combined two posts from this user, joined at the ellipsis, to better convey their overall argument.

${ }^{7}$ Necro posting' is a slang term used to describe when a user replies to a post that has not been active for a long time (Know Your Meme n.d.). This brings old material to other users' attention since the page will be marked as containing new content.
} 